\title{
Opaque Idioms in Arabic and English: A Perspective Analysis of their Semantic Anomaly
}

\author{
Dr. Abdalla Elkheir Elgobshawi \\ Assistant Prof. Applied Linguistics \\ 1. Faculty of Science and Humanities \\ Prince Sattam bin Abdulaziz University - Kingdom of Saudi Arabia \\ 2. Faculty of Arts, Sinnar university-Republic of the Sudan \\ PO box 710 Postal Code 11912, Al-Aflaj Kingdom of Saudi Arabia \\ Tel: 966-537-334-046 E-mail: gobshawi@yahoo.com
}

Received: April 27, 2018 Accepted: May 20, 2018 Published: May 27, 2018

doi:10.5296/jsel.v6i1.13207ＵRL: https://doi.org/10.5296/jsel.v6i1.13207

\begin{abstract}
This paper provides a semantic contrast of opaque idioms in Arabic and English. It focuses on idioms that have anomalous nature and it traces out their idiosyncratic features. Linguistic analysis of opaque idioms sets for its task the recognition and examination of the metaphorical and the etymological resources of these idioms. The researcher has chosen for his data some idioms that satisfy the criterion set forth for identifying opaque idioms. Such idioms do not yield their meaning from the meanings of their constituents words. In addition, they lack clues to the understanding their meaning. The semantic analysis of these idioms reveals that the features underling such idioms could not be conventionalized and categorized according to regular rules. They have a metaphorical formulation which in most cases could only be attributed to folkloric and etymological interpretations. Instead, they generally need to be treated in isolation because each of these idioms has its own peculiarities.
\end{abstract}

Keywords: opaque idioms, semantic anomaly, metaphor, etymology, semi transparent idiom 


\section{Macrothink}

\section{Introduction}

\subsection{Identifying Idioms}

Idioms are a controversial issue in linguistic research. This could best be seen in the different definitions and classifications that results in a massive category of words and phrases which all assume to bear the character of an idiom. Furthermore, they (i.e. idioms) have not yet acquired recognition as full standardized linguistic forms.

As for the question of definition of the term 'idiom' it is defined (Gobshawi:12-24) according to different syntactic and semantic criteria but most definitions take an idiom as a phrase that generally has a fixed structure and a non-literal meaning. This anomalous nature of idioms is the cause of many of problems. They ( i.e. idioms) cannot be treated the same way other types of fixed expressions are treated simply because idioms allow syntactic operations only very scarcely. As for the semantic aspect of idioms, the difficulty relates to their non-compositionality as their meaning is odd to the meaning of the words that constitute them.

Relevant linguistic research provides suggestions that liquidize the scope of this term. We find that the term ' idiom' as to Moon [Moon 1998:pps 3,4] is generalized to include many kinds of multiword items whether semantically opaque or not. Moon, however, narrows the scope of idioms and restricts it to particular kind of unit: one that is fixed and semantically opaque or metaphorical, or, traditionally, 'not the sum of its parts', [ ibid:4]. Similar identification of idioms is also reported in (Nattinger \& DeCarrio 2001), (Kuiper \& Allan 1996) and (Glucksberg 2001) where idioms are identified by their fixed syntactic structure and opaque semantic meaning.

The "enological nature" of idioms (McCarthy 1998:129) sets idioms apart from most other fixed expressions. McCarthy gives a more elaborated definition of idioms sophisticating the definitions so far discussed. He referred to the word idiom to mean:

" a string of more than one word whose syntactic, lexical and phonological form is to a greater or lesser degree fixed and whose semantic and pragmatic functions are opaque and specialized also to a greater or lesser degree"[p 129].

Excluding McCarthy's definition of idioms, the definitions so far mentioned are linguistically framed that they only provide information about the semantic and syntactic structure of idioms (their form). McCarthy's definition, in the researcher's view, is thoroughly comprehensive because incorporates lexical, syntactic, semantic and pragmatic identification of idioms.

The wide scope resulting from the different definition of an idiom has produced in turn different classifications of idioms. This lack of clear identification is also marked in sources of basic linguistic information ( dictionaries). As noted by Moon "dictionaries in the Anglo-American tradition often call FEIs 'idioms', making no further typological classification." ( Moon ibid:4)

Idioms are classified according to different criteria including a wide range of words and 
phrases and a great number of syntactic patterns which might be confusing and overlapping. The inclusion of such expressions in the scope of idioms makes it hard to distinguish idioms from non-idioms because they constitute a huge formulaic class of phrases that frequently appear in speech routines. Idioms need to be distinguished from other fixed expressions and a classification that narrows the scope of idioms will help to make easily recognizable.

\subsection{Idiomaticity in Arabic}

Arabic, on the other hand, is typically a rhetorical language and the study of rhetoric is one of its core interests. This interest can be traced in early classics of the Arabic literary works such as 'Thimar Algloub' (Fruits of Hearts) by Altha'alibi and "Asas al-Balaghah" ("The Foundation of Eloquence") by Al-Zamakhshari. Although the terms "idiom" or "idiomatic expression" have not been mentioned, but instances of expressions which bear the characteristics of the currently so called idiomatic expressions frequently occur in these works. This frequency could be attributed to the fact that idioms fall into the broad category of metaphoric speech which is an essential guise of Arabic literary production. No single and uniform term is used to express the concept of idioms in early Arabic literary works, instead a number of terms [Alqahtni, 2014:16] appears to indicate idiomatic expressions. These terms include 'proverb' 'saying', 'metonymy' and 'similarity' . The use of these terms has result in widening the scope of idioms in turn; just as seen in the case of western terminology of idioms.

In fact the definition of the term 'idiom' in Arabic does not show any significant difference from the one provided in English language. An idiom is defined in Arabic as a linguistic structure the combined words of which, is not connected with the sense that each of its single words carries. It is an expression that does not accept substitution, delay, omission, or other forms of change of its words. An Idiom is also seen as meaning a 'linguistic pattern, that is characterized by consistency and the consisting of one or more words. It turned from its literal meaning to a different meaning that was set by the speech community' [Elhusseini 2007: 93]. Thus idioms are collocations of special kinds; a word collocates with another to indicate a particular meaning. There is no significant relationship between the syntactic structure of the idiom and its semantic representation because the resulting meaning is only a conventional one and its usage is agreed upon by this speech community. This key role of the speech community in the production of idioms is not fully admitted by some contemporary Arab linguists. Shaheen for instance [ibid 94] argues that The Quran (Muslims' divine source) has introduced words and expressions that bear idiomatic sense. The idiomatic sense of these words and expressions does not rise from conventional usage of the speech community. But, significantly, these idioms of the Quran have occasionally become familiarized in this speech community.

\subsection{The Anomalous Nature of Idioms}

Language is often regarded as an arbitrary system. To begin with, the two words 'arbitrary' and 'system' are themselves odds. Linguistics bears the burden to systematize this arbitrariness of language but idioms seem to go beyond its reach. As seen earlier that they 
have neither a uniform definition nor a well defined class. They are culturally and not linguistically framed and the reasons that give rise to idioms are to be attributed to cultural and pragmatic dimensions rather than to linguistic ones.

The view that idiom develop out from figurative expressions appears to contrast the common linguistic view that idioms are arbitrary. A term frequently adhered to idioms is metaphor. Most idioms are figuratively rooted. And "one of the questions in idiom research is the extent the image component of a figurative idiom fixed in its inner form reaches into its lexicalized meaning and consequently its pragmatics." [Dobrovol'skij and Piiraine 2010:73]

In fact the relevance of metaphor to idioms is seen from different perspectives [ Cruse 41-42 and Hobbs as cited by Cacciari 1988:32]. An idiom is the outcome of the lifecycle that starts from a metaphor and loses its metaphorical origin over time. It (i.e. an idiom) develops over three phases. In the first phase a metaphor is created out of a conceptual domain and is extended to another domain and inferential paths allow it to be interpreted. It becomes familiar and frequently used in the second phase but in the third phase the gap between the two domains broadens and requires a direct link. In the fourth phase the metaphor can no longer be traced from its metaphorical origin of the expression, and the expression is conceived of as a way of denoting the object, action. Cruse further elaborates the relevance of metaphor to idioms when he adds the expression known as frozen or dead metaphor to the category of idioms. He uses these expression not only to indicate this relevance, but also to provide clues for the interpretation of the idioms. He states that "if, however, a metaphor is used sufficiently frequently with a particular meaning, it loses its characteristic or piquancy, its capacity to surprise, and hearers encode the metaphorical meaning as one of the standard senses of the expression. Interpreting it then no longer requires the activation of the metaphorical strategy" [Cruse ibid:42].

Dead metaphors have in common with idioms that their constituent elements do not, in the straightforward sense yield recurrent semantic contrasts:

As for our investigation in the current study we will take the cognitive linguistics argument that idioms are conceptual, and not linguistic, in nature and that they (i.e 'idioms') are "regarded not just as an expression that has meaning that is somehow special in relation to the meanings of its constituent parts, but as something that 'arises from our more general knowledge of the world,' which is embodied in our conceptual system". [Kovecses \&Szabc, 2010:330]

[ibid:327-333]. This conceptual approach appears to contrast to the traditional approach where idioms are assumed to be a matter of language alone and are merely accounted for their syntactic and semantic properties. Accordingly, idioms are characterized the same way words are characterized in the lexicon according to their syntactic properties and meaning, and also taken to be independent of each other. According to this traditional Idiomaticity perspective , idioms[ Abdullah, Khalid 1998:67] are conceptualized as arbitrary expressions-

Abdu [2012] has examined the semantic structure of Arabic idioms and the patterns of semantic extension that underlie them. He has found that the main patterns of semantic 
extension that are involved in the production of Arabic idioms are metaphor, metonymy, interaction of metaphor and metonymy.

The term motivation is introduced to trace how does an expression develop its idiomatic sense out of its literal one. It , as cited by Abdu from Geeraerts "involves the relationship between the original, literal meaning of the constituent parts of the idiomatic expression, and the interpretation that those parts receive within the derived reading of the expression as a whole" [p37]. This relevance of the original literal meaning to the idiomatic meaning indicates dependence on of the transparency that might result from this relevance. A semantic extension of the literal meaning is made when the least possibility of deducing the idiomatic meaning out of the literal one is left.

\subsection{Data and analysis}

The data of this study has been selected from different sources in Arabic and English. The Arabic data is mainly based on Aldhabi's Alfakhir (book on proverbs and idiom) -Al-Zamakhshari' Asas Albalagha (The Foundation of Eloquence). The English data basically selected from-Flavell, \&Linda Roger' Dictionary of Idioms and their Origins in addition to online dictionaries. The bare criterion for the selection of these idioms is that these core or opaque idioms do not by themselves yield their meaning. In addition, they are to be non compositional and lacking clues to the interpretation and understanding of their meaning.

The following sections provides an analysis of the data collected from the above mentioned sources. Selected opaque idioms from the two language will contrastively be examined to reveal similarities and dissimilarities between opaque idioms in these languages. The examination of these idioms is made by identifying their semantic anomaly and by tracing their metaphorical and etymological origins. The anomalous nature of idioms can best be exemplified when the meaning of the target idiom is unmotivated "that native speakers cannot establish links between its literal and idiomatic reading" [ ibid:38].

1.4.1. Arabic idioms of such kind frequently appears in the Quran. istaghsh thiyabah, which literally means to wrap one's clothes about oneself/fold one's garments around oneself. The idiomatic sense is [to show indifference. The image is that of person who is presented with a message but who, instead of listening to it, wraps his garments around himself and takes off, thus showing indifference to what is being said [see Mir page 248]. In English an idiom with a similar meaning is to give (someone) the cold shoulder [Flavell 1994:59] which means to behave in an unfriendly way towards someone, to snub someone or to be unenthusiastic about an idea. The idioms will be tackled later in this section.

1.4.2. In Arabic they use the expression "كأن عل رؤوسهم الطير ka?an ela ruwasihim altayr to refer to someone who stands motionless in solemnity. The literal meaning of the expression is 'if there are birds on their heads'. The origin of this Arabic idiom [see Alrazi 1986:169] refers to their claim that the crow stands on the head of the camel to remove ticks and other vermin from it. The camel should not, then, move and so that the crow does alienate from it. The meaning which corresponds to this image is the state of being still and motionless. English language, in contrast, does have an equivalent opaque idiom with such a meaning but the 
semi transparent idiom is to be in awe of carries a similar sense. According to Ammer [ Ammer 1986] be in awe of or stand in awe of is an idiomatic expression that means to respect and revere someone or something or to experience a feeling of solemn wonder. "This expression dates from about A.D. 1000 and originally meant "fear something or someone." Later awe came to mean "dread mingled with respect," and eventually it signified reverence alone". [ page 520].

1.4.3. Of the infamous Arabic structures is عقيرته فلان "رفع" [Al-Sakakini, 2012:77] rafae flan eaqiratah: meaning that ' $\mathrm{X}$ ' raises up his voice. The word 'eaqira' ( literally means a leg being cut) indicates voice in the context of the idiom. Nothing in this article indicates this sense for in the story of this expression is that a man once has one of his legs cut off in the market . He lifted it up and began to cry loudly in pain . It is, then, when his loud crying is coincided with the raising of his leg the expression has become common in raising the voice in crying. An English idiom with a close meaning is at the top of ones lungs is to speak with an extremely loud voice. This idiom is a semi transparent one upon considering its inclusion the organ of speech (i.e. lung).

1.4.4. In the Arabic expression "halumm jara", the word 'halumm' is a verb which and join us. It is a supplication for someone to do something, ' jarra' is to drag someone or to encourage them to do something. The story of this idiom relates to a cunning method or a temptation to let camels and sheep graze in pasture along their path when taken to market. So the idiomatic sense of the expression is to be steadfast in your path, do not strain yourselves. It is not intended to refer here to the sensory state of coming, but rather to continue doing something ( that presumably positive or good) and to keep doing it in that frequent manner.

1.4.5 In Arabic language the expression " أسلم رجليه للريح aslam rijlayh lilriyh, literally and lexically means; he gives his feet to the wind, take to one's heels, and its idiomatic sense is to flee away quickly, take to one's heels or to run away. The English idioms which carries a similar meaning is ' run like the wind' meaning to escape quickly. The metaphoric image of this idiom may be created on basis of the view that the wind is generally associated with swift speed in people religious and folkloric memory and the fact that legs are, the body part that perform the act of running. The etymology of the phrase suggests the cutting of the anchor rope of a ship to make a quick departure from a harbor before the wind . This term originally "..about 1700 meant to cut a vessel's anchor cable and make sail at once. By the mid-1800s it was being used figuratively. Charles Dickens had it in Great Expectations (1861): "I'd give a shilling if they had cut and run." [ Ammer . 1992: 142].

1.4.6. The English idiom Cash on the hoof seems to originate from the cattle industry.

If someone in the cattle industry needs to raise some quick cash the animals can be sold at the owner's discretion to generate cash and unlike other crops do not have to be harvested when mature.

The phrase might also be a modified form of 'cash on the nail' (or 'pay on the nail'), from (The Phrase Finder at www.phrases.org.uk ) which itself is an extension of the earlier phrase - 'on the nail', meaning immediate payment; without delay. The term also appears in in the world of business or horse racing with obvious relevance to money. The Arabic counterpart of 
this idiom is النقد عند الحافره 'alnaqd eind alhafir' literally means cash on the hoof and idiomatically denoting that payment is to be made at the first word or immediately. The phrase originally refers to the selling of horses that when a horse is sold the seller asks the buyer to pay before the trace or the hole made on the earth by the hoof of the horse disappears (before the departure). The term was earlier used for horses because they were the best things sold but later generalized to indicate immediate payment in business deals. [Al-Zamakhsha.1988:492]

Another interpretation of the origin of this phrase is provided by Almufadal (see Alfakhir page 56). This interpretation is built on a homophone of the word 'alhafir'. The same word in Arabic refers to a digger. An earth digger is anticipated to report on soil fertility or infertility. That resembles the checking and evaluation of a sold item which is necessary for satisfaction and dissatisfaction the selling process.

1.4.7. The idiom a pig in a poke to divulge a secret inadvertently. It relates to buying without first inspecting or a purchase that was not properly examined. A custom [Flavell ibid:146] for selling pigs was that one pig would be used shown as a sample and the rest would be neatly tied in sacks, or 'pokes', but some of the sellers would put cats instead. Some customer would be fooled by the trick and only discover the deception later, but the more wary fellow would untie his sack to check his purchase.

The idiom in Arabic that might be equivalent to this idiom is "يأخذه على حين غرة" yakhudhh ealaa hin ghira ( to deceive and fool someone). The word 'ghira' in Arabic means unwariness. The semantic scope and the concept embedded in the concept of the Arabic idiom is much closer to the English one.

1.4.8. The Arabic expression ' طوى كثحه tawa kashhu gives a similar meaning as to turn the cold shoulder. The two expressions use body parts. In Arabic language the gesture ' طوى كثحه ' (to turn away by one'e ....waist) indicates turning away from someone. It is used with an idiomatic sense to indicate lack of intimacy. The Arabic word 'الكاشح' alkashih is conceptualized as a person who feels hatred against someone. The word (i.e. 'الكاشتح') is derived from the word 'كثخ ' kashh meaning waist and it collates with the word 'طوى' to fold). According to the Arabic phrase the waist seems to fold his hostility or a person may turn his waist away to show lack of intimacy. In English an idiom with a similar meaning is to turn/give a cold shoulder. To give a cold shoulder which originated in the early 1800s has a quite different sense[Flavell 1994:49 ]. As hospitality custom at that time guests were welcomed to a house and were served a hot meal but those who overstayed their welcome were served a cold shoulder of whatever meat was being eaten. The shoulder was undesirable part of the animal.

1.4.9. The Arabic idiom ' فلان ضيق العطن' flan dayq al-Atan illustrates a stingy person. The word Atan literally refers to the place where camels kneel around to drink water [Alfakhir 507]. Accordingly a wealthy man's atan is bigger and more wet. A poor person, in contrast, uses a smaller and less wet one. The word atan is metonymized to indicate the wealth state of camel owners and the whole phrase is generalized to refer to an individual's richness or poverty. The phrase is idiomatized to refer to a sting person and in case he is dayq al-Atan and a generous 
one in the other. The idiom also applies to characterize personality and a person is said to be irascible or good tempered.

English language does not have a direct corresponding idiom to the Arabic one discussed above. Instead many idiomatic words and phrases carry a similar meaning. The word tightwad (at www.etymologynline.com) for example is used to describe a stingy and parsimonious person. In the combination 'tightwad' the word 'tight' indicates the figurative sense of close-fisted and ' wad' 'indicating a mass or quantity of something. Then, with this sense, someone tightly grasping money in fist, bears the character of a stingy person.

1.4.10. The English idiom raining cats and dogs is a typical of opaque idioms. Though this idiom satisfies the criterion set forth to be categorized among opaque idioms, but its idiomatic sense is quite familiar. May this could be attributed to its quite frequency of use and also to the familiarity it has acquired due to its frequent illustration in linguistic research and language teaching materials.

One of theories of the origin of this idiom [see Flavel ibid: 157 and Hendrickson.2008: 696 ] is the one that relates it to heavy rains in England in the 17th- century. Due to lack of adequate drainage at that time, some of the city streets turned into filthy rivers with dead bodies of stray dogs.

The constituents that make up the expression it rains cats and dogs could also be subject to some religious and mythological interpretations. In The Holy Quran the word rain is reported many time to indicate a negative sense.[ see Alamri.2010:40,41]. It ( i.e. word rain) comes in the context of punishment, torture and torment whereas the word 'alghayth' is frequently indicates mercy.

As for the mythological interpretation the expression was inspired by some facts about cats and dogs in Northern mythology for they were closely associated with the rain and wind in Northern mythology, dogs often being pictured as the attendants of Odin, the storm god, while cats were believed to cause storm[ Hendrickson.ibid: 696 ]

\section{Conclusion}

The study aims at contrasting idiom in English and Arabic. It focuses on particular types of idioms, namely opaque idioms. They (i.e. opaque idioms) are characterized a set of characteristics but most obviously of these is that their semantics does not correspond to their lexical structure. The researcher has chosen for his data some idioms that satisfy the criterion set forth for identifying opaque idioms. Such idioms do not yield their meaning from the meanings of their constituents words. In addition, they lack clues to the understanding their meaning. The analysis of these idioms reveals that they are irregular semantic patterns. They have a metaphorical formulation which in most cases could only be attributed to folkloric and etymological interpretations. The perceptions underlying the significance and composition of these idioms could best be with regard to their cultural context and usage occasions . It seems 
that these idioms generally need to be individually because each of these idioms has its own peculiar nature.

\section{References}

Abdalla, Khalid. (1998). The Analysis and Classification of English Idioms. (Doctoral dissertation).Birmingham: University of Central England. Retrieved from https://www.researchgate.net/publication/33775298

Abdu, Ashraf. (2012). Arabic Idioms A Corpus Based Study. New York: Routledge

Alamri, Khaleel. (2010). Alsiyaq: Anmatuh wa Tatbiqatuh fi Alta'abir Alqurani . (Context Patterns and their Applications in the Koranic Expression) Qadisiyah Journal of Arts \& Sciences, 6(2), 37-63. Retrieved 7. 4. 2017, from iasj.net/iasj?func=fulltext\&aId=13474

Aldhabi, Almufadal. (2011). Alfakhir. Beirut: Dar Alkotob Al-llmiayh. Print.

Alqahtni, Hijab Mohammad. (2014). The Structure and Context of Idiomatic Expressions in the Saudi Press. (Doctoral dissertation). The University of Leeds. Retrieved from http://etheses.whiterose.ac.uk/7678/

Alrazi, Abu Bakr. (1986:169). Mukhtar Alsahah . Beirut, Lebanon: Maktabat Lebnan.

Al-Sakakini, Khalil. (2012). Muta'at fi Allugha wa Al-Adab. (Readinds in Language \& Literature) Cairo: Hindawi Foundation for Education and Culture.

Al-Zamakhsha, A. Gassim. (1998). Asas Albalagha, (Basics of Eloquence) Beirut: Dar Alkotob Al-llmiayh.

Dobrovol'skij, D., \& Piirainen, E. (2010). Idioms: Motivation and etymology. Yearbook of Phraseology, 2010, pp. 73-96 Retrieved 5 April. 2017, from https://doi.org/10.1515/9783110222623.1.73

Elgobshawi, A. Elkheir. (2012). An investigation into difficulties of understanding and using English idioms facing Sudanese students majoring in English language. ( Doctoral dissertation). Sudan University of Science and Technology. Retrieved from http://repository.sustech.edu/handle/123456789/5977

Elhusseini, Hamada. (2007). Almusahabat Allughawia wa Aathariha fI Tahdid Aldalala fi Alquran Alkarim. (Linguistic Accompaniment and its Significance Effect In the Holy Quran" Theoreticaland Applied Study). (Doctoral dissertation). The University of Al-Azhar. Retrieved from: www.alukah.net/researches/files/rsrch_353/almosaheba-alghawya.pdf

Flavell, \& Linda Roger. (1994). Dictionary of Idioms and their Origins. London: Kyle Cathie Ltd.

Glucksburg, Sam, \& McGloned. (2001). Understanding Figurative Language: From Metaphor To Idioms. New York: Oxford University Press. 


\section{Macrothink}

Harper, Douglas. "Online Etymology Dictionary." Online Etymology Dictionary. N.p., 2000. Web. 21 Nov. 2016.

Hendrickson, Robert. (2008). The Facts on File Encyclopedia of Word and Phrase Origin. New York, U.S.A: InfoBase Publishing.

Kovecses, Zoltan \& Szabc, Peter; Idioms: A View from Cognitive Semantics Appl Linguist 1996; 17(3), 326-355. https://doi.org/10.1093/applin/17.3.326

Martin, Gary. "The Meanings and Origins of English Phrases, Sayings and Proverbs in Everyday Use." Phrasefinder. N.p., Dec. 1997. Web. 22 Dec. 2016.

McCarthy, Michael. (1998). Spoken Language and Applied Linguistics. Cambridge: Cambridge University Press.

Mir, Mustansir. (1989). Verbal Idioms of The Quran. Michigan: The University of Michigan.

Moon, Rosamund. (1998). Fixed Expressions And Idioms. Oxford, Clarendon Press,

Nattinger, James, \& Decarrico, Jeanettee S. (2001). Lexical Phrases and Language Teaching. London: Oxford University Pres.

\section{Copyright Disclaimer}

Copyright for this article is retained by the author(s), with first publication rights granted to the journal.

This is an open-access article distributed under the terms and conditions of the Creative Commons Attribution license (http://creativecommons.org/licenses/by/3.0/). 